\title{
Inclusive education: Global priority, collective responsibility
}

\author{
Yao Ydo ${ }^{1}$
}

Accepted: 27 October 2020 / Published online: 20 November 2020

(C) UNESCO IBE 2020

Just over ten years ago, a special issue of Prospects was dedicated to the theme of inclusive education. It appeared right after the 48th session of the International Conference on Education (ICE), with its theme "Inclusive Education: The Way of the Future". This conference, which took place in Geneva in 2008, and was organized by UNESCO International Bureau of Education (IBE), focused on ways of providing education to the hundreds of millions of people around the world with little or no access to learning opportunities. The long-term objective was to support UNESCO Member States in providing the social and political conditions which every person needs in order to exercise their human right to access, take an active part in and learn from educational opportunities.

During the conference, ministers, government officials, and representatives of non-governmental organizations discussed the importance of broadening the concept of inclusion to reach all children, under the assumption that every learner matters equally and has the right to receive effective educational opportunities (Opertti et al. 2014). In this way, greater clarity was achieved regarding the idea of inclusive education.

\section{Inclusion and equity}

In many countries, inclusive education is still thought of as an approach to serving children with disabilities within general education settings. Following the lead provided by the IBE conference in 2008, however, it is increasingly seen more broadly as a principle that supports and welcomes diversity among all learners. This means that the aim is to eliminate the exclusion that is a consequence of attitudes and responses to diversity in race, social class, ethnicity, religion, gender, sexual orientation, migrant status, and ability. As such, it starts from the belief that education is a basic human right and the foundation for

Yao Ydo

ibe.prospects@unesco.org

1 UNESCO International Bureau of Education, P.O. Box 199, 1211 Geneva 20, Switzerland 
a more just society-hence the more recent emphasis on equity, which implies a concern with fairness.

Moving forward, 2016 was a particularly important year in relation to the inclusion agenda. Building on the Incheon Declaration agreed at the World Forum on Education in May 2015, it saw the publication by UNESCO of the Education 2030 Framework for Action (UNESCO 2015). This emphasizes inclusion and equity as laying the foundations for quality education. It also stresses the need to address all forms of exclusion and marginalization, disparities and inequalities in access, participation, and learning processes and outcomes.

The importance of including children with disabilities is an essential strand within this international policy agenda. This was stressed in the United Nations Convention on the Rights of Persons with Disabilities (United Nations 2006), which states: "The right to inclusive education encompasses a transformation in culture, policy and practice in all educational environments to accommodate the differing requirements and identities of individual students, together with a commitment to remove the barriers that impede that possibility" (General Comment 4). Inclusion also implies greater emphasis on the medium of instruction, as promoting mother tongue-based multilingual education is key to quality lifelong learning opportunities for all. Equally important, inclusion implies the need to close the "digital divide", by improving digital access and help all students develop digital and media literacy. Inclusion commits to ending segregation within educational settings by ensuring inclusive classroom teaching in accessible learning environments with appropriate support. This means that education systems must provide a personalized educational response rather than expecting the student to fit the system.

A renewed commitment reinforcing inclusion and equity in education was expressed at an International Forum, co-organized by UNESCO and the Colombian ministry of education in September 2019, to mark the 25th anniversary of the Salamanca World Conference on Special Needs Education. As underlined by the theme "Every learner matters", the Forum was an opportunity to revive the broadened notion of inclusion as a general guiding principle to strengthen equal access to quality learning opportunities for all learners.

\section{Setting the agenda}

In this special issue of Prospects, scholars from around the world examine progress in implementing this thinking in various contexts. More specifically, they analyze these experiences in relation to the three justifications for inclusive education outlined in a recently published UNESCO report, "Towards Inclusion and Equity in Education: Status, Trends, and Challenges" (UNESCO 2020b), which states that there is:

- An educational justification: The requirement for schools to educate all children together means that they have to develop ways of teaching that respond to individual differences and that therefore benefit all children.

- A social justification: Inclusive schools are intended to change attitudes to difference by educating all children together, and form the basis for a just and non-discriminatory society.

- An economic justification: It is likely to be less costly to establish and maintain schools that educate all children together than to set up a complex system of different types of school specializing in particular groups of children. 
The articles in this special issue address one overall question: What evidence is there to support these arguments? They do this in the context of a diverse range of countries and regions. At the same time, they focus on a wide range of children and young people who are seen to be vulnerable to marginalization, exclusion, and low achievement. Together, the articles throw light on positive developments that can inform thinking, policy, and practice in the field, as well as the challenges that exist in implementing these ideas.

\section{This special issue}

Like all major policy changes, progress in relation to inclusion and equity requires an effective strategy for implementation. In particular, it requires new thinking that focuses attention on the removal of barriers experienced by some children that lead them to become marginalized as a result of contextual factors. The implication is that overcoming such barriers is an important means of development forms of education that are effective for all children. In this way, an emphasis on inclusion and equity becomes a way of achieving the overall improvement of education systems, as signaled by the OECD (2012, p. 14):

The evidence is conclusive: equity in education pays off. The highest performing education systems across OECD countries are those that combine high quality and equity. In such education systems, the vast majority of students can attain high level skills and knowledge that depend on their ability and drive, more than on their socioeconomic background.

With this theme in mind, I am grateful to Professor Mel Ainscow for guest editing this special issue of Prospects. For the past 30 years or so, he has played an important role in the efforts of UNESCO to promote the idea of inclusive education globally, linking this to the overall improvement of education systems. He was closely involved in the design of three major events: (1) the Salamanca Conference on Special Needs Education in 1994; (2) the 48th session of the IBE International Conference on Education in 2008; and, more recently, (3) the International Forum co-organized by UNESCO and the Colombian ministry of education in September 2019, to celebrate the 25th anniversary of the Salamanca Declaration.

During the 1990s, Mel led the development of the teacher-training materials "Special Needs in the Classroom" on behalf of UNESCO, which involved initiatives in over 80 countries (UNESCO 1993). And, more recently, he led the production of the UNESCO publication A Guide for Ensuring Inclusion and Equity in Education (UNESCO 2017), which offers practical support to member states to help review how well equity and inclusion currently figure in existing policies, decide what actions need to be taken to improve policies, and monitor progress as actions are taken. Related to this guide, Mel also coordinated the production for the IBE of Reaching Out to All Learners (UNESCO IBE 2016), a set of resource materials intended to influence and support inclusive thinking and practices at all levels of an education system.

\section{A global priority}

The agenda of this special issue has become an even greater global priority as the world responds to the massive challenges that have emerged as a result of the pandemic crisis. This has thrown new light on the urgent need to develop education systems that are 
designed to include all of our children and young people. In this sense, the task is not about returning to normality. Rather, it is an opportunity to create a "new normal", fueled by lessons learned during this period of global crisis. As argued by Nóvoa and Alvim (2020, p. 6), "Many educators and families were already aware of the need to change the school model, but the pandemic revealed the urgency and the possibility of this transformation".

Insights into the existing global situation in relation to the need for transformation are provided in the recent Global Education Monitoring Report (UNESCO 2020a), a summary of which is provided in this special issue. The report assesses progress towards Sustainable Development Goal (SDG) 4, as well as other related education targets in the SDG agenda. In particular, it examines progress in relation to inclusion in education, drawing attention to all those excluded because of their background or personal characteristics.

The GEM 2020 report is informed by the explicit reference to inclusion in the 2015 Incheon Declaration and the call to ensure an inclusive and equitable quality education in the formulation of SDG 4, the global goal for education. It reminds us that, no matter what argument may be built to the contrary, we have a moral imperative to ensure that every child has a right to an appropriate education of high quality. In so doing, it argues that "debating the benefits of inclusive education can be seen as tantamount to debating the benefits of the abolition of slavery, or indeed of apartheid" (UNESCO 2020a, p. v).

The GEM 2020 report also explores the challenges holding us back from achieving this vision and provides concrete policy examples from countries managing to tackle them with success. Echoing themes that are addressed in this special edition of Prospects, these challenges include:

- differing understandings of the word inclusion;

- lack of teacher support;

- absence of data on those excluded from education;

- inappropriate infrastructure;

- persistence of parallel systems and special schools;

- lack of political will and community support;

- untargeted finance;

- uncoordinated governance;

- multiple but inconsistent laws;

- policies that are not being followed through.

\section{Collective responsibility}

In her introduction to the GEM 2020 report (UNESCO 2020a), Audrey Azoulay, DirectorGeneral of UNESCO, emphasizes the urgent need to address these challenges:

It has never been more crucial to make education a universal right, and a reality for all. Our rapidly-changing world faces constant major challenges-from technological disruption to climate change, conflict, the forced movement of people, intolerance and hate-which further widen inequalities and exert an impact for decades to come. The Covid-19 pandemic has further exposed and deepened these inequalities and the fragility of our societies.

She goes on to conclude that, more than ever, we have a collective responsibility to support the most vulnerable and disadvantaged learners. I hope that the articles in this special issue 
of Prospects will provide encouragement and inspiration to researchers, policy makers, and practitioners in moving this agenda forward.

\section{References}

Nóvoa, A., \& Alvim, Y. (2020). Nothing is new, but everything has changed: A viewpoint on the future school. Prospects. https://doi.org/10.1007/s11125-020-09487.

Opertti, R., Walker, Z., \& Zhang, Y. (2014). Inclusive education: From targeting groups and schools to achieving quality education as the core of EFA. In L. Florian (Ed.), The Sage handbook of special education (2nd revised ed., pp. 149-170). London: Sage.

OECD (2012). Equity and quality in education: Supporting disadvantaged students and schools. Paris: OECD. https://www.oecd.org/education/school/50293148.pdf.

UNESCO (1993). Special needs in the classroom: A teacher education guide. Paris: UNESCO. https:// unesdoc.unesco.org/ark:/48223/pf0000135116.

UNESCO (2015). Incheon declaration and framework for action for the implementation of Sustainable Development Goal 4. Paris: UNESCO. https://unesdoc.unesco.org/ark:/48223/pf0000245656.

UNESCO IBE [International Bureau of Education] (2016). Reaching out to all learners: A resource pack for supporting inclusive education, training tools for curriculum development. Geneva: UNESCO IBE. http://www.ibe.unesco.org/sites/default/files/resources/ibe-crp-inclusiveeducation-2016_eng.pdf.

UNESCO (2017). A guide for ensuring inclusion and equity in education. Paris: UNESCO. https://unesd oc.unesco.org/ark:/48223/pf0000248254.

UNESCO (2020a). Inclusion and education: All means all. Global monitoring report. Paris: UNESCO. https://en.unesco.org/gem-report/report/2020/inclusion.

UNESCO (2020b). Towards inclusion in education: Status, trends and challenges. The UNESCO Salamanca Statement 25 years on. Paris: UNESCO. https://unesdoc.unesco.org/ark:/48223/pf0000374246.

United Nations (2006). Convention on the rights of persons with disabilities. New York, NY: United Nations. https://www.un.org/development/desa/disabilities/convention-on-the-rights-of-persons-withdisabilities.html.

Publisher's Note Springer Nature remains neutral with regard to jurisdictional claims in published maps and institutional affiliations. 